\title{
Article \\ Gynecologic Malignancies in Children and Adolescents: How Common is the Uncommon?
}

\author{
Christoph Wohlmuth ${ }^{1, *}$ and Iris Wohlmuth-Wieser ${ }^{2}$ D \\ 1 Department of Obstetrics and Gynecology, Paracelsus Medical University Salzburg, 5020 Salzburg, Austria \\ 2 Department of Dermatology, Paracelsus Medical University Salzburg, 5020 Salzburg, Austria; \\ iris.wohlmuth-wieser@outlook.com \\ * Correspondence: christoph.wohlmuth@outlook.com; Tel.: +43-(0)-5-7255-24900; Fax: +43-(0)-5-7255-24983
}

Citation: Wohlmuth, C.;

Wohlmuth-Wieser, I. Gynecologic

Malignancies in Children and

Adolescents: How Common is the

Uncommon? J. Clin. Med. 2021, 10,

722. https://doi.org/10.3390/

jcm10040722

Academic Editor: Angelo Cagnacci

Received: 4 January 2021

Accepted: 10 February 2021

Published: 12 February 2021

Publisher's Note: MDPI stays neutral with regard to jurisdictional claims in published maps and institutional affiliations.

Copyright: (c) 2021 by the authors. Licensee MDPI, Basel, Switzerland. This article is an open access article distributed under the terms and conditions of the Creative Commons Attribution (CC BY) license (https:// creativecommons.org/licenses/by/ $4.0 /)$.

\begin{abstract}
The aim of this study is to assess the projected incidence and prognostic indicators of gynecologic malignancies in the pediatric population. In this population-based retrospective cohort study, girls $\leq 18$ years with ovarian, uterine, cervical, vaginal and vulvar malignancies diagnosed between 2000 and 2016 were identified from the Surveillance, Epidemiology and End Results (SEER)18 registry. The Kaplan-Meier method was used to analyze overall survival (OS). The age-adjusted annual incidence of gynecologic malignancies was 6.7 per 1,000,000 females, with neoplasms of the ovary accounting for $87.5 \%$, vagina $4.5 \%$, cervix $3.9 \%$, uterus $2.5 \%$ and vulva $1.6 \%$ of all gynecologic malignancies. Malignant germ-cell tumors represented the most common ovarian neoplasm, with an increased incidence in children from 5-18 years. Although certain subtypes were associated with advanced disease stages, the 10-year OS rate was $96.0 \%$. Sarcomas accounted for the majority of vaginal, cervical, uterine and vulvar malignancies. The majority of vaginal neoplasms were observed in girls between $0-4$ years, and the 10 -year OS rate was $86.1 \%$. Overall, gynecologic malignancies accounted for $4.2 \%$ of all malignancies in girls aged 0-18 years and the histologic subtypes and prognosis differed significantly from patients in older age groups.
\end{abstract}

Keywords: gynecologic malignancies; pediatric cancer; gynecologic cancer; pediatric; adolescent; female

\section{Introduction}

Malignant neoplasms are the fifth most common cause of death among children and adolescents aged 0-18 years and the third most common cause when excluding infants $<1$ year [1,2]. Gynecologic malignancies, including ovarian, uterine, cervical, vaginal and vulvar cancer, have been well described in the general population, and treatment guidelines have been tailored to clinical-, stage- and histology-based characteristics [3-6]. With successful advances in cancer therapy, survival is improving and fertility-preserving treatment options have become a critical aspect in the management of women with cancer in reproductive ages [7]. This aspect is also critical in young girls with cancer, but data on gynecologic malignancies in childhood remains scarce. While prospective trials including GOG-10, 45, 90 and 116 allowed for the inclusion of children and adolescents with certain gynecologic cancer subtypes and analyses from pediatric oncology cooperative groups assessed treatment outcome, there is a paucity of epidemiologic data and real-world prognosis [8-15].

The aim of this study was to systematically describe the epidemiology, histologic types and prognosis of gynecologic malignancies in this age group.

\section{Materials and Methods \\ 2.1. Study Population}

The Surveillance, Epidemiology and End Results (SEER) database of the National Cancer Institute was used to identify cases of gynecologic malignancies in children and adolescents. The SEER-18 population (including Atlanta, Connecticut, Detroit, Hawaii, 
Iowa, New Mexico, San Francisco-Oakland, Seattle-Puget Sound, Utah, Los Angeles, San Jose-Monterey, Rural Georgia, the Alaska Native Tumor Registry, Greater California, Greater Georgia, Kentucky, Louisiana and New Jersey) from its November 2018 submission was used. This was limited to cases from 2000-2016 [16].

Patients aged 0-18 years with a diagnosis of invasive cancer of the ovaries, uterus, cervix, vagina and vulva were identified in the SEER ${ }^{*}$ Stat 8.3.6 database, and their clinical data was retrieved. In situ malignancies were excluded. Only patients with known age and listing in the research database were included.

Patients' age at diagnosis, year of diagnosis, ethnicity, site, histology, stage (i.e., localized, regional and distant disease) and survival data were collected. Histologic subtypes were grouped into squamous cell carcinoma, adenocarcinoma, melanoma, sarcoma, germ-cell tumors and other subtypes/unspecified for vulvar, vaginal, cervical and uterine malignancies. Ovarian neoplasms were classified as epithelial, sex-cord-stromal germ-cell or mesenchymal tumors.

Incidence rates were adjusted for age to the 2000 United States standard population and reported per 1,000,000 women 18 years or younger. Patients with secondary gynecologic cancers were excluded from the survival analysis. The SEER data is publicly available and deidentified and therefore excluded from Ethics Board approval.

\subsection{Statistics}

Descriptive statistics were used to report demographic data. Continuous variables were compared using the Mann-Whitney-test or Wilcoxon test, as appropriate. More than two groups were compared using the Kruskal-Wallis ANOVA test. Cross-tables and Chi-square test were used to compare categorical data. The Kaplan-Meier method with log-rank test was used to analyze overall survival. Overall survival was calculated from the date of diagnosis to the date of death. Statistical analysis was performed using SPSS Version 26, IBM, Armonk, USA. A $p$-value $\leq 0.05$ was considered statistically significant.

\section{Results}

Gynecologic malignancies accounted for $4.2 \%(1255 / 29,919)$ of all malignancies in girls $\leq 18$ years and $0.3 \%(1255 / 382,510)$ of all gynecologic malignancies in the SEER-18 population occurred in this age group: $1.1 \%$ of all ovarian, $1.0 \%$ of all vaginal, $0.1 \%$ of all cervical, $0.1 \%$ of all vulvar and $<0.1 \%$ of all uterine malignancies were diagnosed in girls $\leq 18$ years.

The age-adjusted incidence of gynecologic malignancies and the relative frequency by organ are shown in Table 1.

Table 1. Age-adjusted incidence and relative frequency of gynecologic malignancies among children and adolescents $0-18$ years of age.

\begin{tabular}{ccc}
\hline Type of Malignancy & $\begin{array}{c}\text { Incidence } \\
\text { per 1,000,000 Women } \mathbf{( 9 5} \% \mathbf{C I})\end{array}$ & Relative Frequency \% \\
\hline All gynecologic malignancies & $6.719(6.352-7.101)$ & $100 \%$ \\
Ovarian malignancies & $5.882(5.540-6.241)$ & $87.5 \%$ \\
Uterine malignancies & $0.170(0.116-0.240)$ & $2.5 \%$ \\
Cervical malignancies & $0.262(0.193-0.346)$ & $3.9 \%$ \\
Vaginal malignancies & $0.298(0.225-0.388)$ & $4.5 \%$ \\
Vulvar malignancies & $0.106(0.065-0.164)$ & $1.6 \%$ \\
\hline
\end{tabular}

Incidence adjusted to the 2000 United States standard population. Relative frequency of cancer among all gynecologic malignancies in children and adolescents $0-18$ years of age.

Histologic subtypes identified were germ-cell tumors (71.6\%), epithelial carcinomas $(12.4 \%)$, sarcomas $(7.9 \%)$, sex-cord stromal tumors $(6.1 \%)$ and other/unspecified subtypes $(2.1 \%)$. The majority of ovarian neoplasms were germ-cell tumors, whereas sarcomas represented the most common histologic type in uterine, cervical, vaginal and vulvar malignancies. The distribution of histologic subtypes is shown in Figure 1. 


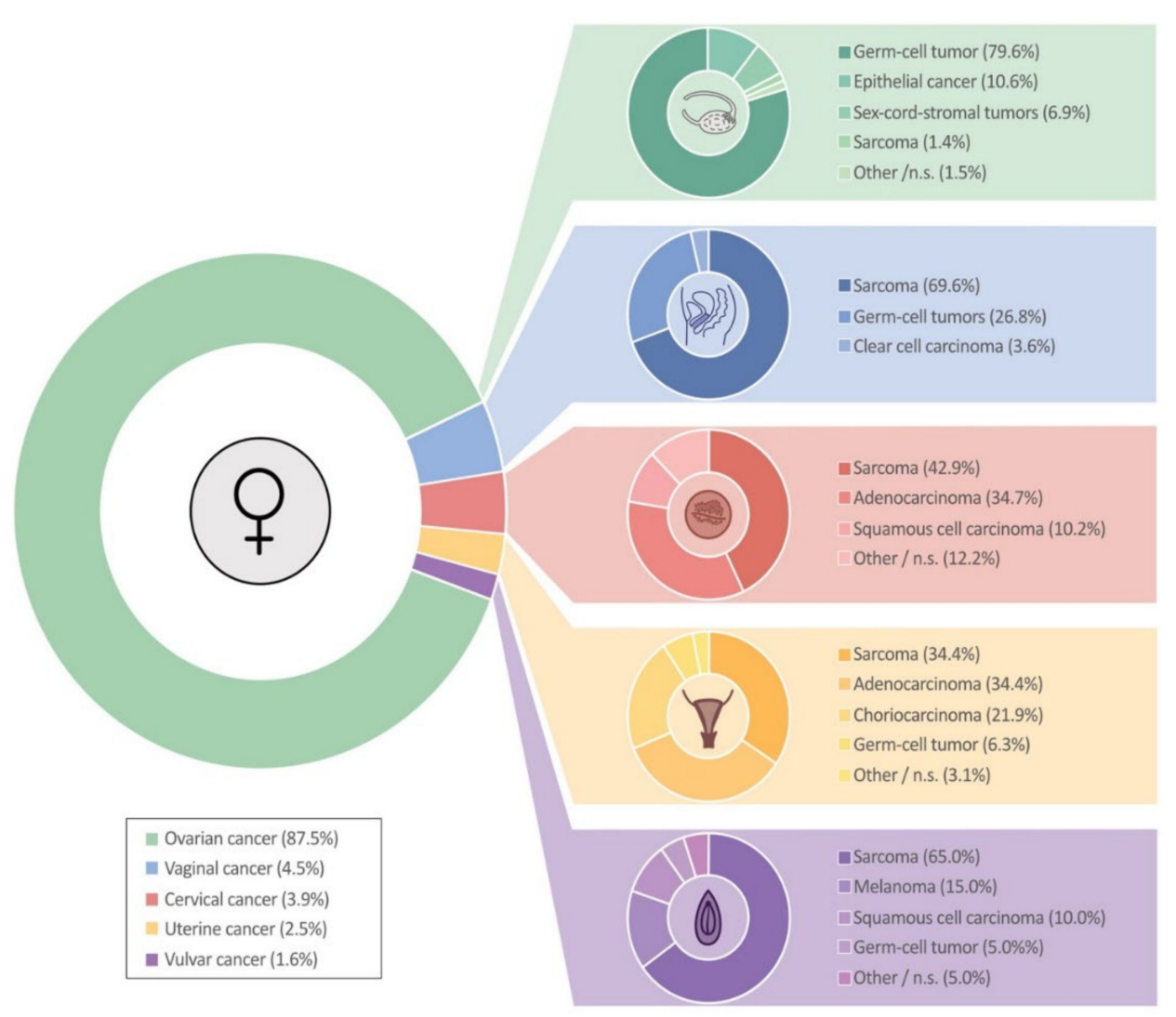

Figure 1. Distribution of gynecologic malignancies according to histology.

Ovarian cancer accounts for $87.5 \%$ of gynecologic malignancies in children and adolescents $\leq 18$ years, vaginal cancer $4.5 \%$, cervical cancer $3.9 \%$, uterine cancer $2.5 \%$ and vulvar cancer $1.6 \%$. Abbreviations: n.s., not specified.

Age at diagnosis and ethnicity differed significantly between patients with cancers of the ovary, uterus, cervix, vagina and vulva. Age at diagnosis and the relative frequency and standardized incidence ratio of gynecologic malignancies stratified by ethnicity are shown in Table 2. Girls with vaginal cancer were significantly younger than all other organ sites $(p<0.001)$, and girls with ovarian cancer were significantly younger than those with uterine malignancies $(p=0.011)$. Age at diagnosis differed between histologic groups $(p<0.001)$. Girls with sarcomas were significantly younger than all other histologic types $(p<0.001)$. Girls with germ-cell tumors were significantly younger than girls with epithelial $(p<0.001)$, sex-cord-stromal tumors $(p=0.026)$ and other/non-specified histologic types $(p=0.019)$. The annual incidence of gynecologic cancers by age is shown in Figure 2A. Disease stage differed between gynecologic sites $(p=0.041$ ) and among ovarian neoplasms (Figure 2B,C). Approximately $19 \%$ of ovarian and uterine cancers were already metastasized at the time of diagnosis. The majority of cervical, vaginal and vulvar cancers were localized.

Table 2. Demographic characteristics by organ.

\begin{tabular}{|c|c|c|c|c|c|c|}
\hline Parameter & $\begin{array}{c}\text { Ovary } \\
(n=1098)\end{array}$ & $\begin{array}{l}\text { Uterus } \\
(n=32)\end{array}$ & $\begin{array}{r}\text { Cervix } \\
(n=49)\end{array}$ & $\begin{array}{l}\text { Vagina } \\
(n=56)\end{array}$ & $\begin{array}{c}\text { Vulva } \\
(n=20)\end{array}$ & $p$ \\
\hline \multicolumn{7}{|l|}{ Age (years) } \\
\hline Mean age $\pm S D$ & $13.7 \pm 3.7$ & $15.3 \pm 4.0$ & $15.0 \pm 3.2$ & $3.4 \pm 4.8$ & $11.5 \pm 6.9$ & \multirow[b]{2}{*}{$<0.001$} \\
\hline Median age (range) & $15.0(0-18)$ & $16.5(1-18)$ & $16.0(6-18)$ & $1.5(0-17)$ & $15.5(1-18)$ & \\
\hline \multicolumn{7}{|l|}{ Ethnicity (\%) } \\
\hline White & $41.0 \%$ & $43.8 \%$ & $30.6 \%$ & $58.9 \%$ & $45.0 \%$ & \multirow{6}{*}{0.029} \\
\hline Black & $13.9 \%$ & $12.5 \%$ & $26.5 \%$ & $17.9 \%$ & $5.0 \%$ & \\
\hline Hispanic & $33.8 \%$ & $40.6 \%$ & $36.7 \%$ & $16.1 \%$ & $45.0 \%$ & \\
\hline Asian or Pacific Islander & $9.5 \%$ & $3.1 \%$ & $0.0 \%$ & $5.4 \%$ & $5.0 \%$ & \\
\hline American Indian or Alaska Native & $0.6 \%$ & $0.0 \%$ & $2.0 \%$ & $1.8 \%$ & $0.0 \%$ & \\
\hline Unknown & $1.2 \%$ & $0.0 \%$ & $4.1 \%$ & $0.0 \%$ & $0.0 \%$ & \\
\hline
\end{tabular}


Table 2. Cont.

\begin{tabular}{ccccccc}
\hline Parameter & $\begin{array}{c}\text { Ovary } \\
(\boldsymbol{n}=\mathbf{1 0 9 8})\end{array}$ & $\begin{array}{c}\text { Uterus } \\
(\boldsymbol{n}=\mathbf{3 2})\end{array}$ & $\begin{array}{c}\text { Cervix } \\
(\boldsymbol{n}=\mathbf{4 9 )}\end{array}$ & $\begin{array}{c}\text { Vagina } \\
(\boldsymbol{n}=\mathbf{5 6})\end{array}$ & $\begin{array}{c}\text { Vulva } \\
(\boldsymbol{n}=\mathbf{2 0})\end{array}$ & $\boldsymbol{p}$ \\
\hline Ethnicity (Incidence per 1,000,000) & & & & & & \\
White & 4.966 & 0.151 & 0.164 & 0.383 & 0.098 \\
Black & 5.830 & 0.153 & 0.488 & 0.400 & 0.040 & n.a. \\
Hispanic & 7.148 & 0.253 & 0.346 & 0.153 & 0.167 & 0.062 \\
Asian or Pacific Islander & 6.515 & 0.061 & 0 & 0.186 & 0 & \\
American Indian or Alaska Native & 3.462 & 0 & 0.499 & 0.498 & 0 \\
\hline
\end{tabular}

Incidence adjusted to the 2000 United States standard population. Abbreviations: SD, standard deviation.
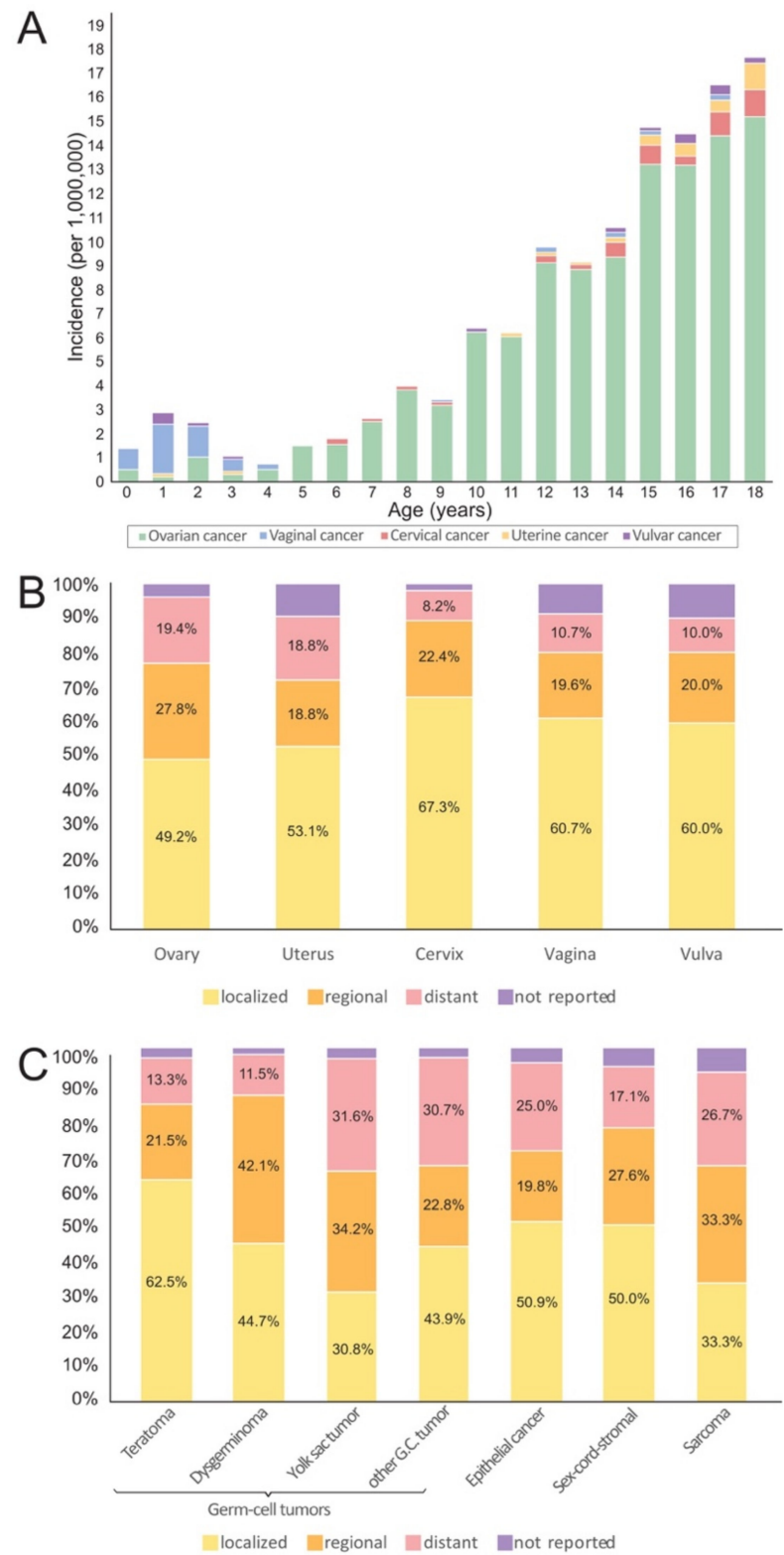

Figure 2. (A-C) Annual incidence of gynecologic malignancies by age from 0-18 years and distribution of disease stage at diagnosis. Abbreviations: n.a., not applicable. (A) The graph illustrates the annual incidence of ovarian, vaginal, cervical, uterine and vulvar cancer by age groups from 0-18 years per 1,000,000 women. (B) Distribution of disease stage of ovarian, vaginal, cervical, uterine and vulvar cancer in children and adolescents from 0-18 years of age. (C) Distribution of disease stage in ovarian malignancies by underlying histologic subtype in the same cohort. Abbreviations: G.C., germ-cell. 
The overall prognosis of gynecologic malignancies in girls $\leq 18$ years is good. The 5 -year overall survival rate for malignancies of the ovary is $92.4 \%$, uterus $85.9 \%$, cervix $87.2 \%$, vagina $90.8 \%$ and vulva $76.9 \%$. The Kaplan-Meier plot of overall survival by organ site is shown in Figure 3A and ovarian, uterine, cervical, vaginal and vulvar cancer by histologic groups in Figure 3B-F.

A

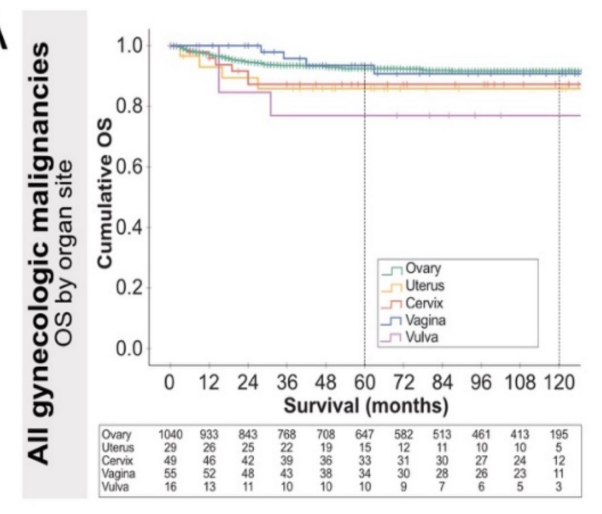

C

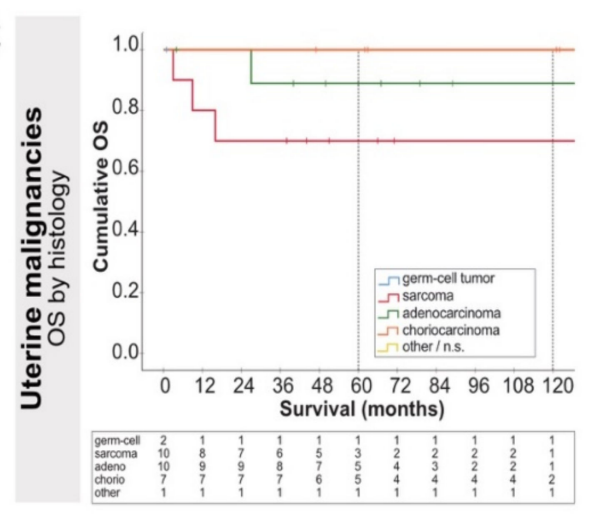

$E$

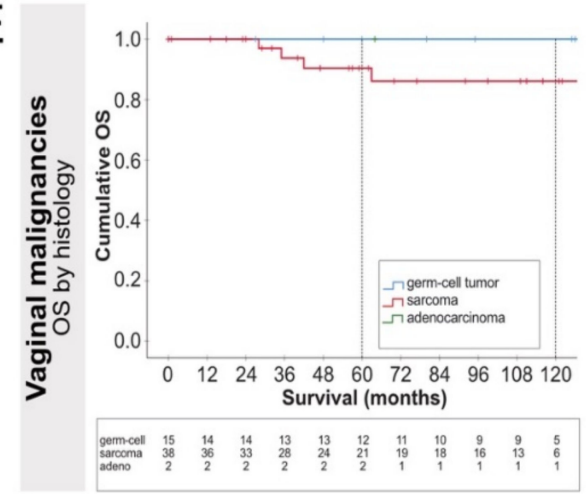

B

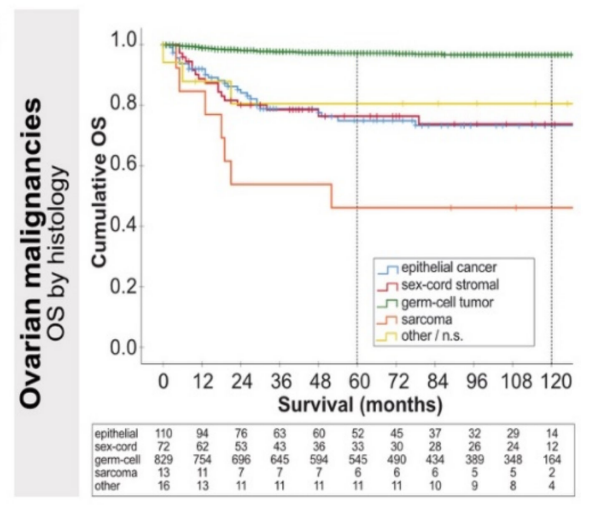

D

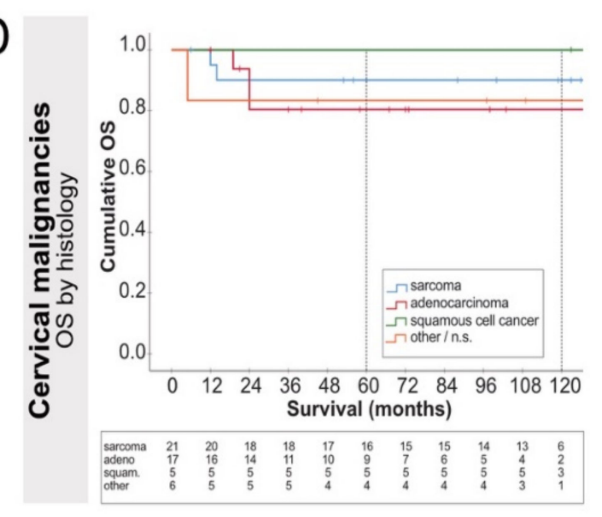

F

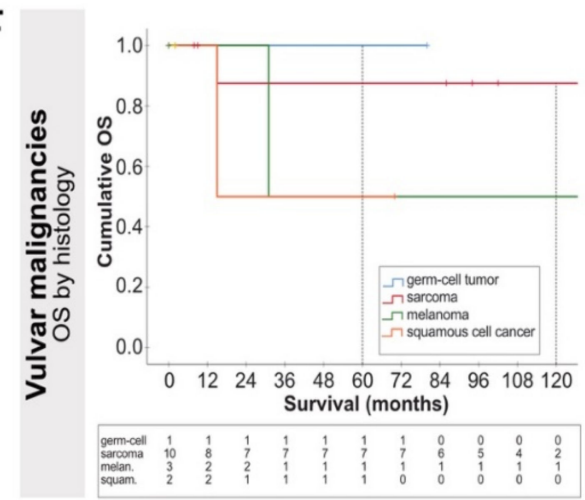

Figure 3. (A-F) Kaplan-Meier plots for 5- and 10-year overall survival for children and adolescents with gynecologic malignancies. (C) The survival curves of germ-cell tumor and choriocarcinoma are overlapping. (E) The survival curves of adenocarcinomas and germ-cell tumors are overlapping. Abbreviations: n.s., not specified; OS, overall survival.

\section{Discussion}

In this study, we used the SEER-18 registry representing $27.8 \%$ of the US population to characterize the epidemiology, demographics and prognosis of gynecologic malignancies in children and adolescents [16]. We have shown that gynecologic malignancies account for $4.2 \%$ of all malignancies in girls $\leq 18$ years. $1.1 \%$ of all ovarian cancers and $1.0 \%$ of all vaginal cancers in the general population are diagnosed in children and adolescents. 
These tumors differ significantly from common gynecologic malignancies encountered in the general population. We have observed a significant difference in the relative frequency of these malignancies among ethnic groups (Table 2). The incidence of cervical cancer was almost three times higher in black and American Indian or Alaska native and two times higher in Hispanic than in white girls. Vaginal cancer was more common in white, black and American Indian or Alaska native than in Hispanic and Asian girls.

\subsection{Ovarian Malignancies}

While the majority of "adulthood" ovarian malignancies are epithelial cancers [17,18], approximately $80 \%$ of all ovarian neoplasms in children and adolescents $\leq 18$ years are germ-cell tumors (Figure 1). These cancers are observed with increasing incidence in children from 5-18 years. Although a significant proportion of yolk sac tumors, dysgerminomas and malignant teratomas are diagnosed at advanced disease stages (Figure 2B), the prognosis is excellent, with 5- and 10-year overall survival rates of $97.2 \%$ and $96.0 \%$ (Figure 3B). Ovarian sarcomas, which are often associated with a poor prognosis, represent a minority of ovarian tumors (Figure 3B). Epithelial and sex-cord-stromal tumors account for approximately $11 \%$ and $7 \%$, respectively, and have a 10-year overall survival rate of $67.5 \%$ and $67.8 \%$, respectively (Figure 3B). As ovarian malignancies are associated with a good prognosis, fertility-preserving treatment options must be considered for these patients. Data indicate that in appropriately selected cases, these treatments do not compromise oncological safety $[19,20]$. Staging and optimal patient selection are a prerequisite. Patients should therefore be referred to dedicated cancer centers to facilitate a multidisciplinary assessment and optimized delivery of care [20-22]. While amenorrhea is a common sideeffect of certain chemotherapy regimens even in younger women, normal menstruation following primary fertility-sparing surgery and platinum-based chemotherapy has been reported in $80-99 \%$ of patients with germ-cell tumors $[23,24]$. In a recently published study of 105 ovarian germ-cell tumor survivors, over $90 \%$ of women $<40$ years of age who desired pregnancy became pregnant and gave birth [25].

\subsection{Vaginal Malignancies}

Vaginal malignancies represent the second most common gynecologic cancer in this age-group, and the majority ( $84 \%$ ) affect children between 0 and 4 years of age (Figure 2A). Sarcomas (mainly embryonal rhabdomyosarcomas) represent the most common histologic subtype (Figure 1), are commonly diagnosed at localized disease stages and are associated with a good prognosis [26]. The 10-year overall survival rate is $86.1 \%$ (Figure 3E), which is similar to a sub-analysis of female genital tract rhabdomyomas from the Intergroup Rhabdomyosarcoma Study Group (IRSG) protocols I-IV [27] and a study combining data from five trials and registry data [11].

Germ-cell (and specifically yolk sac) tumors represent the second most common vaginal histology and have an excellent prognosis. A 10-year overall survival rate of $100 \%$ was observed in this cohort. This finding was similar to a recent single-center case series of 16 patients, where all patients, other than one who experienced a treatment-related death, had a complete response without recurrence at a median follow-up of 53 months (range, 19-223) and is similar to the outcome in malignant germ cell tumors of the ovary, where the reported mortality rate was $1.9 \%$ over a period of 20 years [14,28].

\subsection{Cervical Malignancies}

In this study, sarcomas were also found to be the most common histologic subtype of cervical neoplasms. The majority of these were embryonal rhabdomyosarcomas with a similar prognosis (Figure 3D) and treatment approach as vaginal sarcomas [26,27]. The second most common histologic subtype was adenocarcinoma, and 15 of 16 cases were cervical clear cell cancers. A strong association with intra-uterine diethylstilbestrol (DES) exposure has been shown [29], but several cases have been reported unrelated to DES, particularly in young patients [30-33]. 


\subsection{Vulvar Malignancies}

The majority of vulvar malignancies were sarcomas, which had a very similar prognosis to vaginal and cervical sarcomas (Figure $3 \mathrm{E}, \mathrm{F}$ ) and were treated in a similar fashion [27,34]. Squamous cell cancer and malignant melanoma of the vulva have a poor prognosis. Vulvar melanomas are associated with more advanced disease stages at diagnosis and worse outcomes than cutaneous melanomas [34-36].

\subsection{Uterine Malignancies}

Uterine malignancies are rare in childhood compared to the general population, where they represent the most common gynecologic cancer [17]. We observed a heterogenous group of sarcomas, adenocarcinomas and choriocarcinomas, the latter being more frequently found in teenagers [37]. Treatment strategies depend on the underlying histology [26].

\subsection{Summary}

This study included a large series of gynecologic malignancies in children and adolescents using the SEER-18 population and is representative of the North American population. The data are population-based and therefore not limited to single-center experiences, avoiding publication bias. The study is, however, limited by its retrospective design and the use of registry data, which preclude a central pathology review. In addition, the medical treatment approaches used in this population are not reported here. The scope of this study was to investigate the epidemiology, characteristics and real-world prognosis, and is reflected in our results.

Although gynecologic malignancies in children and adolescents are considered rare, they account for $4.2 \%$ of all malignancies in girls aged $0-18$ years. Approximately $1 \%$ of all ovarian and vaginal cancers encountered in the general population affect this age group. The histologic subtypes of the reported pediatric malignancies differ from the commonly reported gynecologic cancers in the adult population. Treatment decisions should be based on a multi-disciplinary evaluation including pediatric and gynecologic oncologists. With regards to ovarian cancers, germ cell tumors represent the most common ovarian neoplasm. In vulvo-vaginal, uterine and cervical malignancies, sarcomas represent the most common subtype compared to squamous and adenocarcinomas in the adult populations. Overall survival in this study was found to be excellent; therefore, counseling for fertility preserving therapies is encouraged.

Author Contributions: Conceptualization: C.W.; Methodology: C.W., I.W.-W.; Analysis and Data curation: C.W., I.W.-W.; Writing: C.W., I.W.-W. All authors have read and agreed to the published version of the manuscript.

Funding: Iris Wohlmuth-Wieser is supported by a grant from the Austrian Science Fund (FWF), project number J-4382. Open access funding was provided by the Austrian Science Fund (FWF).

Institutional Review Board Statement: The SEER data is publicly available and deidentified and therefore excluded from Ethics Board approval.

Informed Consent Statement: The SEER data is publicly available and deidentified and therefore informed consent was not applicable.

Data Availability Statement: The SEER data is publicly available [16].

Conflicts of Interest: The authors declare no conflict of interest.

\section{References}

1. Cunningham, R.M.; Walton, M.A.; Carter, P.M. The major causes of death in children and adolescents in the United States. N. Engl. J. Med. 2018, 379, 2468-2475. [CrossRef] [PubMed]

2. CDC Wonder. Wide-Ranging Online Data for Epidemiologic Research (WONDER). Available online: https://wonder.cdc.gov/ (accessed on 29 November 2020). 
3. Morgan, R.J.; Armstrong, D.K.; Alvarez, R.D.; Bakkum-Gamez, J.N.; Behbakht, K.; Chen, L.-M.; Copeland, L.; Crispens, M.A.; DeRosa, M.; Dorigo, O.; et al. Ovarian cancer, version 1.2016, NCCN Clinical Practice Guidelines in Oncology. J. Natl. Compr. Cancer Netw. 2016, 14, 1134-1163. [CrossRef]

4. Koh, W.-J.; Abu-Rustum, N.R.; Bean, S.; Bradley, K.; Campos, S.M.; Cho, K.R.; Chon, H.S.; Chu, C.; Clark, R.; Cohn, D.; et al. Cervical cancer, version 3.2019, NCCN Clinical Practice Guidelines in oncology. J. Natl. Compr. Cancer Netw. 2019, 17, 64-84. [CrossRef] [PubMed]

5. Koh, W.-J.; Abu-Rustum, N.R.; Bean, S.; Bradley, K.; Campos, S.M.; Cho, K.R.; Chon, H.S.; Chu, C.; Cohn, D.; Crispens, M.A.; et al. Uterine neoplasms, version 1.2018, NCCN Clinical Practice Guidelines in oncology. J. Natl. Compr. Cancer Netw. 2018, 16, 170-199. [CrossRef]

6. Koh, W.-J.; Greer, B.E.; Abu-Rustum, N.R.; Campos, S.M.; Cho, K.R.; Chon, H.S.; Chu, C.; Cohn, D.; Crispens, M.A.; Dizon, D.S.; et al. Vulvar Cancer, Version 1.2017, NCCN Clinical Practice Guidelines in oncology. J. Natl. Compr. Cancer Netw. 2017, 15, 92-120. [CrossRef]

7. Dolmans, M.-M. Recent advances in fertility preservation and counseling for female cancer patients. Expert Rev. Anticancer Ther. 2018, 18, 115-120. [CrossRef]

8. Slayton, R.E.; Park, R.C.; Silverberg, S.G.; Shingleton, H.; Creasman, W.T.; Blessing, J.A. Vincristine, dactinomycin, and cyclophosphamide in the treatment of malignant germ cell tumors of the ovary. A gynecologic oncology group study (a final report). Cancer 1985, 56, 243-248. [CrossRef]

9. Williams, S.; Blessing, J.; Moore, D.; Homesley, H.; Adcock, L. Cisplatin, vinblastine, and bleomycin in advanced and recurrent ovarian germ-cell tumors. A trial of the Gynecologic Oncology Group. Int. J. Gynecol. Obstet. 1990, 31, 97. [CrossRef]

10. Williams, S.D.; Kauderer, J.; Burnett, A.F.; Lentz, S.S.; Aghajanian, C.; Armstrong, D.K. Adjuvant therapy of completely resected dysgerminoma with carboplatin and etoposide: A trial of the Gynecologic Oncology Group. Gynecol. Oncol. 2004, 95, 496-499. [CrossRef]

11. Sparber-Sauer, M.; Matle, M.; Vokuhl, C.; Hallmen, E.; Von Kalle, T.; Münter, M.; Timmermann, B.; Bielack, S.S.; Klingebiel, T.; Koscielniak, E.; et al. Rhabdomyosarcoma of the female genitourinary tract: Primary and relapsed disease in infants and older children. Treatment results of five Cooperative Weichteilsarkom Studiengruppe (CWS) trials and one registry. Pediatr. Blood Cancer 2021, e28889. [CrossRef]

12. Minard-Colin, V.; Walterhouse, D.; Bisogno, G.; Martelli, H.; Anderson, J.; Rodeberg, D.A.; Ferrari, A.; Jenney, M.; Wolden, S.; De Salvo, G.; et al. Localized vaginal/uterine rhabdomyosarcoma-results of a pooled analysis from four international cooperative groups. Pediatr. Blood Cancer 2018, 65, e27096. [CrossRef]

13. Martelli, H.; Oberlin, O.; Rey, A.; Godzinski, J.; Spicer, R.D.; Bouvet, N.; Haie-Meder, C.; Terrier-Lacombe, M.-J.; De Toledo, J.S.; Spooner, D.; et al. Conservative treatment for girls with nonmetastatic rhabdomyosarcoma of the genital tract: A report from the study committee of the International Society of Pediatric Oncology. J. Clin. Oncol. 1999, 17, 2117. [CrossRef]

14. Calaminus, G.; Schneider, D.T.; Von Schweinitz, D.; Jürgens, H.; Infed, N.; Schönberger, S.; Olson, T.A.; Albers, P.; Vokuhl, C.; Stein, R.; et al. Age-dependent presentation and clinical course of 1465 patients aged 0 to less than 18 years with ovarian or testicular germ cell tumors; Data of the MAKEI 96 protocol revisited in the light of prenatal germ cell biology. Cancers 2020, 12, 611. [CrossRef] [PubMed]

15. Pommert, L.; Bradley, W. Pediatric gynecologic cancers. Curr. Oncol. Rep. 2017, 19, 44. [CrossRef] [PubMed]

16. Surveillance, Epidemiology, and End Results Program. SEER * Stat Version 8.3.8: SEER 18 Registries, November 2018 Sub. (2000-2016). Available online: https:/ / seer.cancer.gov (accessed on 21 December 2020).

17. Siegel, R.L.; Miller, K.D.; Jemal, A. Cancer statistics, 2019. CA Cancer J. Clin. 2019, 69, 7-34. [CrossRef] [PubMed]

18. Ferlay, J.; Soerjomataram, I.; Dikshit, R.; Eser, S.; Mathers, C.; Rebelo, M.; Parkin, D.M.; Forman, D.; Bray, F. Cancer incidence and mortality worldwide: Sources, methods and major patterns in GLOBOCAN 2012. Int. J. Cancer 2014, 136, E359-E386. [CrossRef] [PubMed]

19. Chan, J.K.; Tewari, K.S.; Waller, S.; Ba, M.K.C.; Shin, J.Y.; Osann, K.; Kapp, D.S. The influence of conservative surgical practices for malignant ovarian germ cell tumors. J. Surg. Oncol. 2008, 98, 111-116. [CrossRef]

20. Ray-Coquard, I.; Morice, P.; Lorusso, D.; Prat, J.; Oaknin, A.; Pautier, P.; Colombo, N. Non-epithelial ovarian cancer: ESMO Clinical Practice Guidelines for diagnosis, treatment and follow-up. Ann. Oncol. 2018, 29, iv1-iv18. [CrossRef] [PubMed]

21. Brown, J.; Friedlander, M.; Backes, F.J.; Harter, P.; O'Connor, D.M.; Rouge, T.D.L.M.; Lorusso, D.; Maenpaa, J.; Kim, J.-W.; Tenney, M.E.; et al. Gynecologic Cancer Intergroup (GCIG) consensus review for ovarian germ cell tumors. Int. J. Gynecol. Cancer 2014, 24, S48-S54. [CrossRef] [PubMed]

22. Ray-Coquard, I.; Brown, J.; Harter, P.; Provencher, D.M.; Fong, P.C.; Maenpaa, J.; Ledermann, J.A.; Emons, G.; Rigaud, D.B.; Glasspool, R.M.; et al. Gynecologic Cancer InterGroup (GCIG) consensus review for ovarian sex cord stromal tumors. Int. J. Gynecol. Cancer 2014, 24, S42-S47. [CrossRef] [PubMed]

23. Gershenson, D.M. Management of ovarian germ cell tumors. J. Clin. Oncol. 2007, 25, 2938-2943. [CrossRef] [PubMed]

24. Jacobson, M.H.; Mertens, A.C.; Spencer, J.B.; Manatunga, A.K.; Howards, P.P. Menses resumption after cancer treatment-induced amenorrhea occurs early or not at all. Fertil. Steril. 2016, 105, 765-772. [CrossRef]

25. Tamauchi, S.; Kajiyama, H.; Yoshihara, M.; Ikeda, Y.; Yoshikawa, N.; Nishino, K.; Utsumi, F.; Niimi, K.; Suzuki, S.; Kikkawa, F. Reproductive outcomes of 105 malignant ovarian germ cell tumor survivors: A multicenter study. Am. J. Obstet. Gynecol. 2018, 219, 385.e1-385.e7. [CrossRef] 
26. Lautz, T.B.; Martelli, H.; Fuchs, J.; Chargari, C.; Smeulders, N.; Granberg, C.F.; Wolden, S.L.; Sparber-Sauer, M.; Hawkins, D.S.; Bisogno, G.; et al. Local treatment of rhabdomyosarcoma of the female genital tract: Expert consensus from the Children's Oncology Group, the European Soft-Tissue Sarcoma Group, and the Cooperative Weichteilsarkom Studiengruppe. Pediatr. Blood Cancer 2020. [CrossRef] [PubMed]

27. Arndt, C.A.; Donaldson, S.S.; Anderson, J.R.; Andrassy, R.J.; Laurie, F.; Link, M.P.; Raney, R.B.; Maurer, H.M.; Crist, W.M. What constitutes optimal therapy for patients with rhabdomyosarcoma of the female genital tract? Cancer 2001, 91, 2454-2468. [CrossRef]

28. Yuan, Z.; Cao, D.; Yang, J.; Keng, S.; Huang, H. Vaginal yolk sac tumors: Our experiences and results. Int. J. Gynecol. Cancer 2017, 27, 1489-1493. [CrossRef] [PubMed]

29. Huo, D.; Anderson, D.; Palmer, J.R.; Herbst, A.L. Incidence rates and risks of diethylstilbestrol-related clear-cell adenocarcinoma of the vagina and cervix: Update after 40-year follow-up. Gynecol. Oncol. 2017, 146, 566-571. [CrossRef]

30. Baykara, M.; Benekli, M.; Erdem, O.; Taskiran, C.; Demirci, U.; Vargol, E.; Gunaydin, Y.; Coskun, U.; Ozet, A.; Buyukberber, S. Clear cell adenocarcinoma of the uterine cervix: A case report and review of the literature. J. Pediatr. Hematol. Oncol. 2014, 36, e131-e133. [CrossRef] [PubMed]

31. Lester, F.C.; Farmer, D.L.; Rabban, J.T.; Chen, L.-M. Radical trachelectomy for clear cell carcinoma of the cervix in a 6-year old: A case report, review, and description of the surgical technique. J. Pediatr. Surg. 2010, 45, e1-e5. [CrossRef] [PubMed]

32. Ahrens, W.A.; Barrón-Rodriguez, L.P.; McKee, M.; Rivkees, S.; Reyes-Múgica, M. Clear cell adenocarcinoma of the cervix in a child without in utero exposure to diethylstilbestrol: A case report and review of the literature. Pediatr. Dev. Pathol. 2005, 8, 690-695. [CrossRef] [PubMed]

33. Abu-Rustum, N.R.; Su, W.; Levine, D.A.; Boyd, J.; Sonoda, Y.; Laquaglia, M.P. Pediatric radical abdominal trachelectomy for cervical clear cell carcinoma: A novel surgical approach. Gynecol. Oncol. 2005, 97, 296-300. [CrossRef] [PubMed]

34. Wohlmuth, C.; Wohlmuth-Wieser, I. Vulvar malignancies: An interdisciplinary perspective. J. Dtsch. Dermatol. Ges. 2019, 17, 1257-1276. [CrossRef] [PubMed]

35. Wohlmuth, C.; Wohlmuth-Wieser, I.; May, T.; Vicus, D.; Gien, L.T.; LaFramboise, S. Malignant melanoma of the vulva and vagina: A US population-based study of 1863 patients. Am. J. Clin. Dermatol. 2019, 21, 285-295. [CrossRef] [PubMed]

36. Wohlmuth, C.; Wohlmuth-Wieser, I.; Laframboise, S. Clinical characteristics and treatment response with checkpoint inhibitors in malignant melanoma of the vulva and vagina. J. Low. Genit. Tract Dis. 2020. [CrossRef]

37. Brinton, L.A.; Bracken, M.B.; Connelly, R.R. Choriocarcinoma incidence in the United States. Am. J. Epidemiol. 1986, 123, 1094-1100. [CrossRef] [PubMed] 